Article

\title{
Coal Industrial Supply Chain Network and Associated Evaluation Models
}

\author{
Ge He, Li Zhou, Yiyang Dai (1), Yagu Dang and Xu Ji * (1) \\ School of Chemical Engineering, Sichuan University, Chengdu 610065, China; hegescu@gmail.com (G.H.); \\ chezli@scu.edu.cn (L.Z.); daiyy@scu.edu.cn (Y.D.); derkdang@scu.edu.cn (Y.D.) \\ * Correspondence: jixu@scu.edu.cn
}

Received: 15 September 2020; Accepted: 9 November 2020; Published: 27 November 2020

\begin{abstract}
To improve integration and achieve better coal industry materials and energy balance, integrated collaborative supply chains (SCs) are needed. However, as single-core SC models are not suitable for complex coal industry systems, a multicore, correlated, conditional SC model, called a supply chain network (SCN), is proposed. SCN collaborative evaluation models are discussed including industrial metabolic balance (IMB), enterprise profitability, contract execution ability and information interaction ability, for which IMB is used as the efficiency index of resource coordination of SCN, also as the constraints of the models on system levels. Further, data modeling by using BP-ANN algorithm is used to predict the profitability of supply chain network. Finally, the feasibility of the above models is illustrated by cases. The proposed evaluation models in this paper form the scientific and quantitative evaluation method of SC, which could be used for both SC planning and operations management helping detect and eliminate risks.
\end{abstract}

Keywords: supply chain network; coal industry; grey relational analysis; neural networks; industrial metabolism balance; collaboration

\section{Introduction}

As a result of technological development trends and the structural characteristics of new energy, the energy industry, which encompasses the coal, oil and gas and new energy industries, needs to find new development modes to respond to the challenges of the ever-increasing environmental requirements and production and marketing and energy-price volatility imbalances [1]. In China, the resource endowment is characterized by rich coal, poor oil and less gas, so the coal industry occupies a dominant position in China's energy consumption. In the past 40 years of economic development, coal accounts for $70 \%$ of energy consumption. The development of the Chinese coal industry can be divided into four stages [2]. The first stage to the fourth stage is the introduction period, growth period, maturity period and decline period. At present, due to the strong constraints on environmental resources and the enhancement of energy substitutability, the market demand for coal has declined [3]. With the reform of government supply side and the improvement of energy structure, the coal proportion has decreased as the share of natural gas and other clean energies has increased, intensifying the coal chemical industry production surplus. In 2014, mining fixed asset investment was USD 0.23 trillion, an increase of $0.7 \%$; however, coal asset investment experienced a decrease of $9.5 \%$ to USD 73.2 billion, the second consecutive year of negative growth (2015 China Mineral Resources, 2015), and in 2015 , average coal industry capacity utilization decreased by $26 \%$. Therefore, the government has issued a series of policies to eliminate backward production capacity, resolve excess capacity and improve the quality of coal supply $[4,5]$. In the coal supply chain involved in the production, supply, transportation, demand and other different links, there are many trading subjects and enterprises, and always through the two-way flow of logistics and capital flow, bank settlement and financing 
demand is huge [6,7]. Enterprise agglomeration and industry integration trends, which have attracted significant research and engineering practice attention, have therefore become important development directions for the coal industry [8]. Supply chain integration has been seen to be a typical solution, with such supply chain (SC) integration and collaboration mainly focused on material movement value chains from raw material suppliers to manufacturers to distributors to retailers and customers $[9,10]$, as shown in Figure 1.

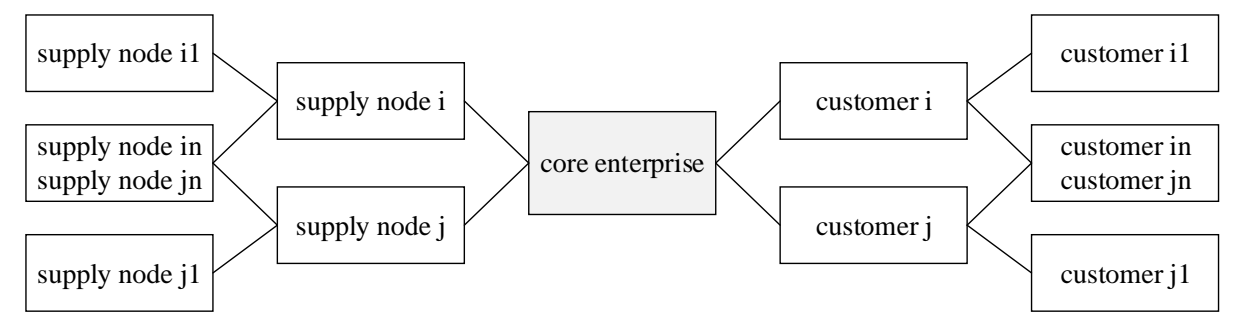

Figure 1. Supply chain model with single core.

Consequently, SC collaborative evaluation has become an important research focus for SC establishment and optimization [11-17]. Lambert et al. indicated that successful SC management depended on the focal members of SC, which integrated SC by four components: planning, control methods, workflow, communication and information flow facility structure. The integration and redesign initiatives of SC should be aimed at promoting efficiency and effectiveness of the whole SC and every member of the supply chain $[18,19]$. Zhang analyzed the influential factor action mechanism in supply chains using self-organization theory, from which SC technology spillover models were established [20]. Kristianto introduced an initial basis for an innovative decision support systems platform which was capable of integrating supply chain system design, management, control and optimization activities [21]. Anbanandam developed a method, which included factors such as management commitment, information sharing, trust between supply chain partners, long-term relationships, as well as risk and reward sharing variables, to measure the collaborative degree between apparel retailers and manufacturers in the retail apparel industry [22]. Zokaee presented a robust optimization model for the design of a supply chain facing uncertainty in demand, supply capacity and major cost data including transportation and shortage cost parameters [23]. Arampantzi propose a new Multi-objective Mixed Integer Linear Programming (MMILP) model, which captures significant decisions involved in designing or redesigning high performance, sustainable supply chains. To solve the proposed model, both goal programming and the e-constraint method to achieve efficient trade-offs among the three objectives are used [24]. However, to date, as most SC research has been business oriented, there have been few energy industry focused studies. In fact, to realize sustainable coal chemical industry development, enterprises need to diversify value and promote industrial chain integration, increasing the complexity of the SC structure [25-27]. The coal chemical industry chain is shown in Figure 2.

The coal chemical industry refers to the process of converting coal into gas, liquid and solid fuels and chemicals, mainly including coal gasification, liquefaction, retorting, tar processing and calcium carbide acetylene chemical industry. In order to realize clean and efficient utilization of coal resources, various technical paths, product categories and market supplies should be integrated and complementary based on the balance of mass, energy, chemical reactions and special market conditions. At the same time, the utilization of waste gas, synthetic tail gas, coal gasification and combustion ash and other wastes and surplus energy are also important. In essence, on each node of SC, the physical form and material composition could be changed obeying the rules of energy and material balance, it is the distinctions between chemical industry supply chain integration and other industry supply chain integration. Therefore, it is difficult to establish a single-core model for a complex supply chain that embraces coal resources, industrial production, consumption as well as environmental factors. As business difficulties by a single enterprise in the coal industrial chain 
can lead to a decrease and/or fluctuation in SC integration, making it difficult to maintain normal operations, constructing collaborative evaluation models adapted to the carbon industry chain would be a more practical solution [28]. To improve the coordination and the robustness of the coal industry chain, the viability of a multicore supply chain and its associated collaborative evaluation models needs to be evaluated based on the coal industry properties.

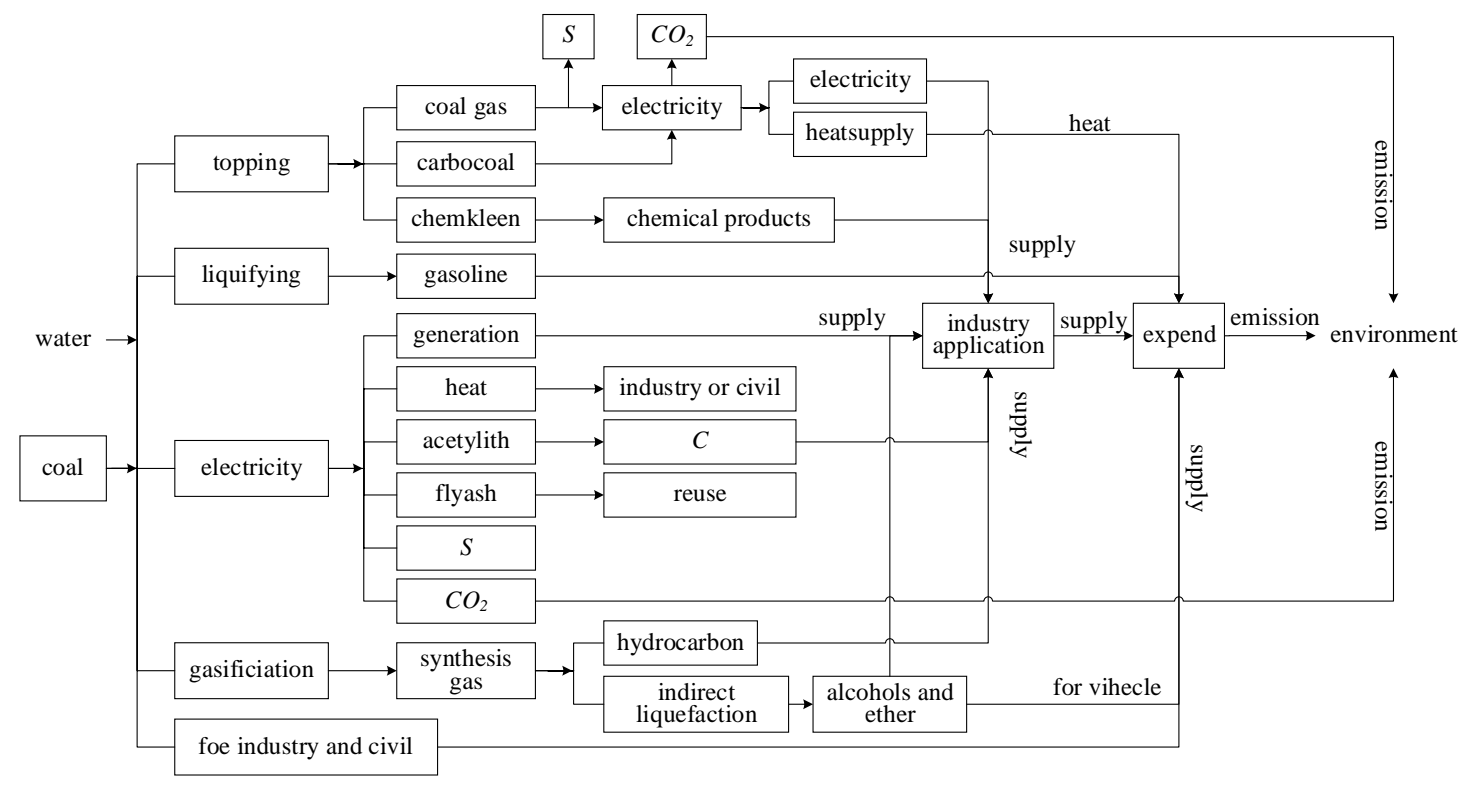

Figure 2. The coal industry chain.

There have been some research interests in the development of multinode SC models. Dan proposed a stochastic programming model for locating distribution centers to adapt to the dynamically changing demands at retailers' sites [29]. Tang analyzed the SC robustness when faced with catastrophic disruption events [30]. Ma proposed an integrated bilevel production-distribution planning model aimed at minimizing total costs on the condition that the core firm plays a key role in deciding which node in the SC serves customers [31]. Herwig identified resources, objects and parameters for supply chain flexibility, and designed and highlighted the potential of a strategic supply chain network to improve SC flexibility [32]. Farahani [33] reviewed and introduced the main features of the models proposed in both supply chain network design (SCND) and competition literature. After investigating the proposed competitive SCND model, a general framework of competitive SCND problem modeling considering management insight is developed, and the potential areas for future research are proposed. Based on the closed-loop supply chain network, Amin [34] propose a mixed-integer linear programming model with minimum total cost, which can be extended to consider environmental factors by weighted sum and a-constraint method. The test results show that the model can deal with demand and return uncertainties, simultaneously. Amin [35] proposed a mathematical model for a closed-loop supply chain network by considering global factors, including exchange rates and customs duties. To design a multiproduct closed-loop green supply chain network consisting of manufacturing/remanufacturing and collection/inspection centers as well as disposal center and markets, Talaei [36] proposed a mixed-integer linear programming model capable of reducing the network total costs. The model has been developed so as to consider such environmental objectives as reducing the rate of carbon dioxide emission in the environment throughout the network in question. $\mathrm{Li}$ et al. [37] take the coal supply chain network as the research object, combined with the carbon emission policy and establish the comprehensive decision-making model for sustainable design of coal supply chain. Through empirical analysis and comparison of four different carbon emission policies on coal supply chain network optimization, it is found that coal enterprises have the best emission reduction effect under carbon trading policy. Ghahremani-Nahr [38] proposed a facility 
location/allocation model for a multiechelon multiproduct multiperiod CLSC network under shortage, uncertainty and discount on the purchase of raw materials. To design the network, a mixed-integer nonlinear programming (MINLP) model capable of reducing total costs of network is proposed. Ahmadzadeh [39] propose a nonlinear programming model based on the three-level closed loop supply chain for location-inventory-pricing decisions and use three meta-heuristic algorithms for solving it namely the genetic algorithm (GA), the imperialist competitive algorithm (ICA) and the firefly algorithm (FA).However, as the above SC models were based on one core firm, these models and methods are unable to meet the evaluation and optimization needs for a complex multicore SC. To improve coal industry industrial structural theory and address the shortage of collaborative evaluation models for the coal industry supply chain network, a new collaborative SC evaluation model will be proposed in this paper which considers industrial metabolic balance, sustainable profitability, enterprise contract execution ability and information interactivity.

The remainder of this paper is organized as follows. Section 2 presents a multicore supply chain, called the SCN and presents a theoretical discussion of the current evaluation models. In Section 3, case studies are presented to analyze the SCN and the associated coal industry evaluation models. Grey relational analysis (GRA) is applied to remove lowly correlated, nonindependent influential factors, and a hybrid GA-BP algorithm is used to establish an enterprise profitability model. Finally, in Section 4, we conclude the paper and discuss future research directions.

\section{Multinode Supply Chain and Collaborative Evaluation Models}

\subsection{Multinode Supply Chain}

As discussed, because of complex product structures, materials cross linking, the rigid constraints for each single chemical process and the need for close collaboration between SC node enterprises, it is difficult to establish stable closed-loop material balance and decision optimization models for coal enterprise groups [40]. To achieve thermodynamic equilibrium, material balances and conditions suitable for the enterprise group, a multicore, correlated, conditional supply chain mode is required to integrate the environmental, industrial and market requirements; a "resource-product-consumptionwaste-renewable resource"; which is composed of a variety of enterprises and correlative entities, all of which are seen as equivalent.

To distinguish the difference from a single-core SC model, the above multicore SC mode is named the supply chain network (SCN). In the $\mathrm{SCN}$, resources, machining, markets, the environment and other related factors are called nodes, each of which is independent but also connected through cooperative contracts and material flows. The connection modes between the nodes are known as a cooperative mode, a competitive mode and a cooperative-competitive mode. The SCN can achieve overall optimal benefit and minimum environmental impacts by balancing resources and energy and integrating production and the market. As there are multiple core enterprises in the SCN, integration and cooperation between the nodes is extremely important. Stable, reliable coordination among the nodes is the most important feature of SCNs, for which codecisions, information sharing, fair competition and benefit equilibrium are the key factors for overall SCN collaborations and optimal performances. SCN coordination evaluation models, therefore, are significantly different to those of a SC.

\subsection{SCN Coordinated Evaluation Models}

Previous studies have shown that partnership diagnoses, reliability analyses and risk identification and assessment are important for general SCN collaborative evaluations. For the coal chemical industry, correlation, conditionality and an atomic economy are the main differences from other industries; therefore, the coal industry supply chain network should be studied from the atomic levels to the system levels to meet the evaluative collaborative needs. In this thesis, the evaluation models for SCN was built based on the three-hierarchized process mechanism models and management models for 
chemical processes, shown as Figure 3, which include dynamic process simulation models, process control models, technical and economic evaluation and decision-making models.

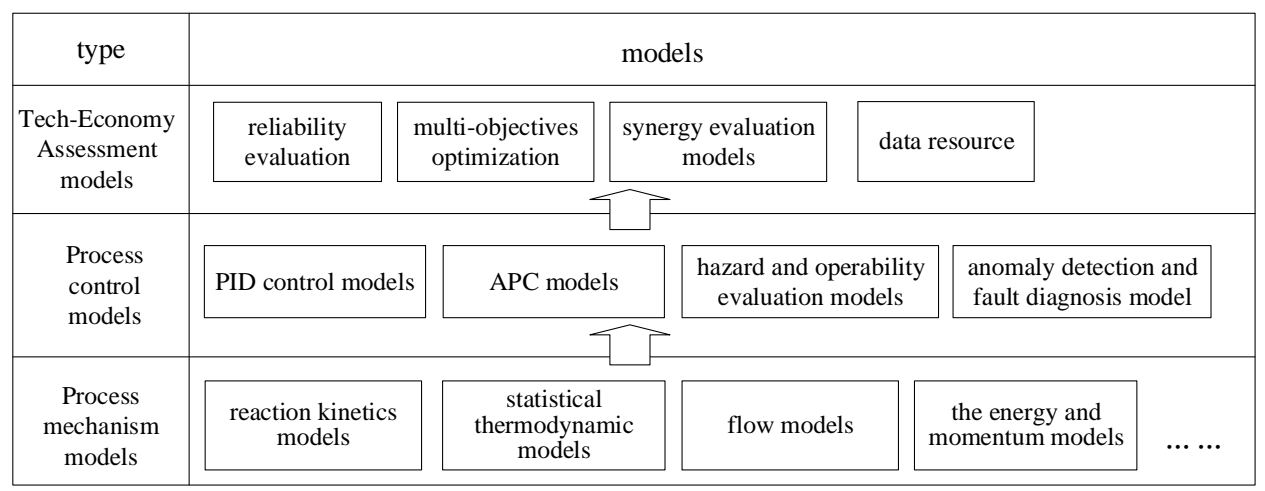

Figure 3. The three-hierarchized models for chemical processes.

\subsubsection{Models for SCN Industrial Metabolic Balance}

Resource recycling and environmental protection, which are directly related to long-term industrial development, are important targets for the energy industry. Industrial metabolism made up of product metabolism and waste metabolism is therefore proposed to assess the environmental impacts of the material and energy flows during the manufacturing process [41,42]. Product metabolism focuses on the production chain to realize its value conversion, while waste metabolism focuses on the waste chain, in which the manufacturing process waste from one process becomes the raw materials for another process for conversion into another product, thereby extending the waste chain and converting waste into valuable materials, improving gains in the production chain. In the coal chemical industry, maintaining the balance between production metabolism and waste metabolism is critical for SCN collaboration [43]. In this study, the SCN industrial metabolic balance was achieved using an effective chemical element utilization rate. The relationship between the material flows is shown in Figure 4.

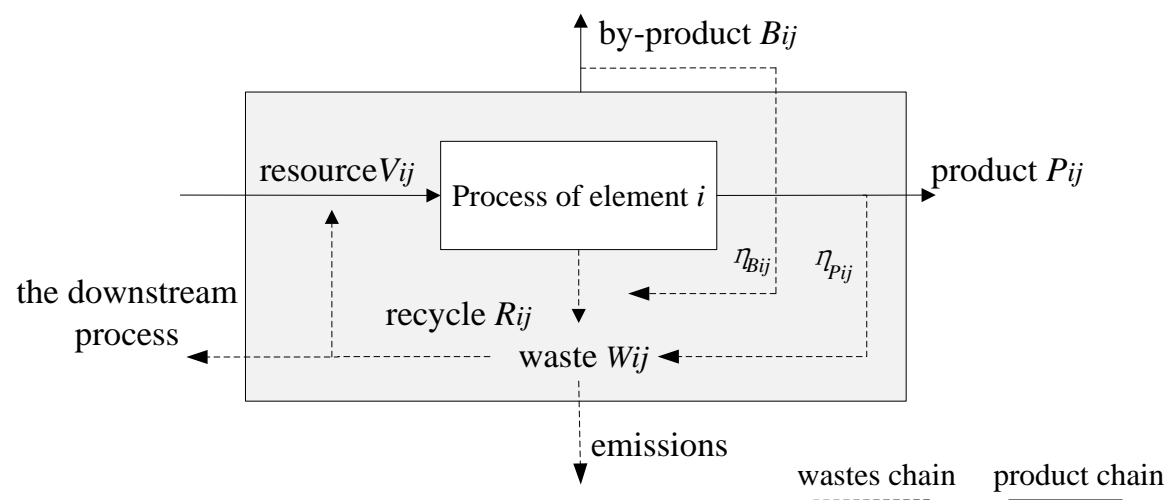

Figure 4. Material flow relationship for chemical process $j$.

For element $i$, the industrial metabolic balance for subsupply chain $j$ is expressed in Formula (1):

$$
E_{i j}=1-\frac{\sum\left(w_{i j}+P_{i j} \times \eta_{p i j}+B_{i j} \times \eta_{B i j}\right)-R_{i j}}{V_{i j}}
$$

where $E_{i j}$ is the industrial metabolic balance for subsupply chain $j$ expressed by element $i ; V_{i j}$ is the inflow of the component; $P_{i j}, B_{i j}$ and $W_{i j}$ are respectively the product flow, the by-products and the wastes; $\eta_{P i j}$ and $\eta_{B i j}$ are the product waste rate and the by-products after consumption and $R_{i j}$ is the recycled quantity. 
The multiple subsupply chains are related to element $i$ in the $\operatorname{SCN}(j=1,2 \ldots, n)$. The SCN comprehensive industry metabolic balance represented by element $i$ can be expressed by Formula (2):

$$
E_{i}=\prod_{j=1}^{n} E_{i j}
$$

Analyzing Equation (1), $E_{i}$ could be increased by reducing $B_{i j}, W_{i j}, \eta_{P i j}$ and $\eta_{B i j}$. Increasing $R_{i j}$ is also an important alternative. In this way, a more complete industrial chain can be established, within which more waste is recycled, thereby improving the collaboration between the upstream industry and the downstream industry.

\subsubsection{SCN Evaluation Models for Sustainable Profitability}

SCN stability depends on the sustainable development and profitability of the enterprises inside the network. If a single enterprise in the SCN falls into difficulty, or its collaboration with other enterprises fails, the overall SCN industrial metabolic balance reduces, affecting supply chain development. Therefore, sustainable profitability is one of the main goals for supply chain network construction and also the main evaluation indicator. As is known, enterprise sustainability requires the integration of decision-making abilities, organizing abilities, execution abilities, partner collaborative abilities and innovation abilities, amongst others. Using cluster analysis and canonical correlation methods, Liu verified the relationships between enterprise operating ability and profitability and development [44]. To address the profitability and sustainability compromise, coal chemistry enterprises need to strengthen their core technical abilities to achieve the goals of structural industrial optimization, energy conservation and environmental protection and recycling. As the key to coal chemical industry profitability, the main focus needs to be on achieving atomic level equilibrium by focusing on the atomic economy within the supply chain network through supply chain network assimilation and node enterprise coordination. Therefore, the evaluation indexes for the supply chain network, such as profitability, development ability and the collaborative degree, must be based on the industrial metabolic balance. The related evaluation models are established in the following.

\section{(1). Development Ability Evaluation Models}

The economic status of a single enterprise can be assessed from its operating revenue, profit, growth trends, total assets, net asset value, debt-paying ability and cash flow. The sustainable development capacity can be assessed through the degree of product differentiation, human resources and R\&D input [45]. The comprehensive SCN development ability evaluation model, therefore, can be expressed by Equation (3):

$$
F_{a}=f(m, e, o, k, g)
$$

where $F_{a}$ is the SCN development ability index and; $m, e, o, k$, and $g$ are customer relationships, decision-making capacity, operating superiority, supply network support and financial profitability of the SCN enterprises, respectively. As SCN enterprises may belong to different areas, function $f$ is established based on actual operating data. In the following case study, a GA-BP was used to establish the model.

\section{(2). Industrial Collaboration Degree Evaluation}

As enterprises in the industrial chain have deterministic interconnections, the flexible operation under the uncertain conditions is the key to achieve industrial collaboration [46], there are some limitation to operating flexibility. The greater the enterprise's industrial collaboration, the greater the $\mathrm{SCN}$ restriction. From the perspective of industrial metabolism balance, its operation-feasible values 
range of $\theta$ decides the size of flexible region of coal chemical process. The SCN industry collaboration degree evaluation model is shown in Equation (4):

$$
\begin{gathered}
F_{b}=f\left(c, v, r, s, p, f_{i}\right) \\
\min _{\theta \in T(\delta)} \max _{i \in I} f_{i}(\bar{d}, \bar{z}, \theta) \leq 0 \\
T(\delta)=\left\{\theta \mid \theta_{i}^{N}-\delta_{i} \Delta \theta_{i}^{-} \leq \theta_{i} \leq \theta_{i}^{N}+\delta_{i} \Delta \theta_{i}^{+}\right\}
\end{gathered}
$$

where $F_{b}$ is the SCN industry collaboration index, $c, v, r, s$ and $p$ are: the conformity between product and service, customer viscosity, delivery reliability, business flexibility, and client satisfaction, respectively. $f_{i}$ is the constraint condition of node $i$ which integrates objective parameters, operating parameters and industrial metabolic balance. $i$ presents the node $i$. Equation (5) presents the minimum operating region for all nodes under the certain metabolic balance. $\bar{d}$ is the vector of design business objectives described by Equation (3) and $\bar{z}$, is the vector of actual operation variables. $\theta$ is the industrial metabolic balance among the SCN enterprises. $T(\delta)$ presented in Formula (6) is the hyper-rectangle describing the range of operation-feasible $\theta . \theta_{i}^{N}$ is the nominal point of node $i, \Delta \theta_{i}^{+}, \Delta \theta_{i}^{-}$are the corresponding positive and negative deviations, $\delta$ is the scalar parameter mainly based on actual operations, respectively. $I$ is the set of all nodes.

For a conventional chemical process, the adjustment strategies of $\bar{z}$ should meet the requirements of the certain range of hyper-rectangle considering the node plant only. While in the $\mathrm{SCN}$, the coordination of multinodes is subject to the more rigorous ranges of $\theta$, and so the adjustable regions of $\bar{z}$ is smaller.

\section{(3). Sustainable Profitability Evaluation}

SCN sustainable profitability is evaluated based on development ability and collaboration, which is expressed by Equation (7)

$$
F=f\left(F_{a i}, F_{b i}\right)(i=1,2, \ldots, n)
$$

where $F_{a i}$ is the development ability index for enterprise $i, F_{b i}$ is the industrial collaboration degree index for enterprise $i . F_{i}$ is the profitability index of enterprise $i$, and $F$ is the aggregative indicator for overall SCN profitability. To evaluate $F$, the following aspects are considered:

For $F$, the SCN industrial metabolic balances are both restraints and influential factors.

Business integration could improve customer viscosity and delivery reliability but could also restrict SCN business flexibility; therefore, the industrial correlative degree models are both goal functions and constraints.

Market demand and resource supply stability as well as competition with enterprises outside the SCN are all influential factors [47].

As product price is an important factor when evaluating enterprise competitiveness in fully competitive conditions, it needs to be compared with the price and manufacturing costs of competing products; therefore, as the manufacturing costs in competing industries are also an important comparative index, oil, natural gas and shale gas prices can substantially influence coal industry operations.

\subsubsection{Evaluation of Enterprise Contract Execution Ability}

$\mathrm{SCN}$ enterprise operations must be consistent with interests across the whole $\mathrm{SCN}$, and must also meet shareholder profit expectations [48]. However, these two demands may conflict and even threaten normal SCN operations. Therefore, an enterprise's ability to execute contracts needs to be analyzed as an enterprise's profitability is the most important influential factor when implementing contracts. The model for an enterprise's ability to execute contracts can be expressed as:

$$
P_{n i}=\frac{F_{i}}{\max \left\{F_{t} \mid t=1,2, \ldots, n\right\}}
$$


where $P_{n i}$ is the contract execution ability of enterprise $i$ facing $n$ competitors and $F_{i}$ is the profitability index for enterprise $i$. The denominator in (6) is the maximum profitability of $n$ related member enterprises both inside and outside the $\mathrm{SCN}$, for which $P_{n i}$ equals 1 when enterprise $i$ has maximum profitability. The ability to execute contracts in the overall SCN is expressed as $P_{n}$, the value for which depends on the relationship between the node enterprises. The fundamental SCN structures are cooperative mode, competitive mode and hybrid cooperative-competitive mode, as shown in Figure 5.

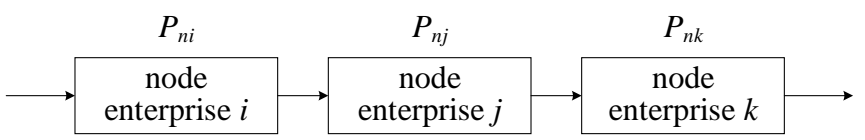

(a) cooperative structure
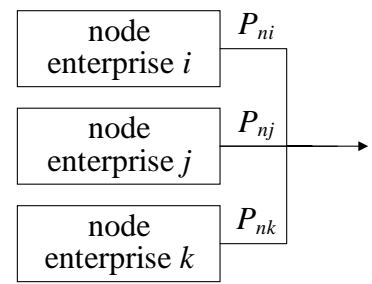

(b) competitive structure

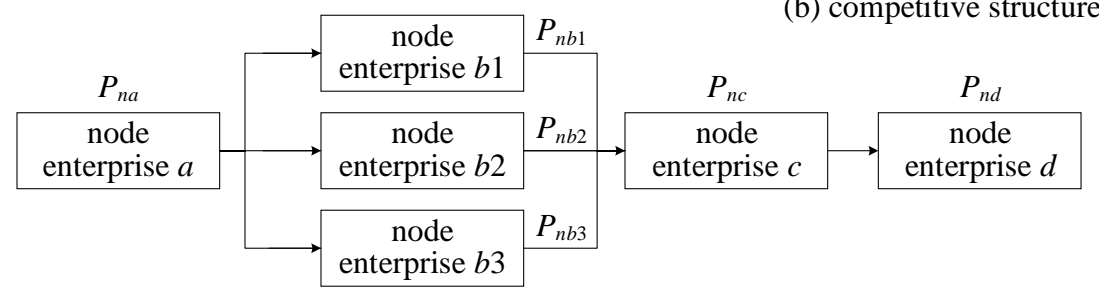

(c) cooperative-competitive structure

Figure 5. Basic supply chain network (SCN) structural models.

The $P_{n}$ for the cooperative structure in Figure 5a can be calculated using Equation (9):

$$
P_{n}=\prod_{i=1}^{n} P_{n i}
$$

The $P_{n}$ for the competitive structure in Figure $5 \mathrm{~b}$ can be calculated using Equation (10):

$$
P_{n}=\min \left\{P_{n i} \mid i=1,2, \ldots, n\right\}
$$

The $P_{n}$ for the cooperative-competitive structure in Figure $5 \mathrm{c}$ can be calculated using Equation (11):

$$
P_{n}=P_{n a} \times\left(\min \left\{P_{n b 1}, P_{n b 2}, P_{n b 3}\right\}\right) \times P_{n c} \times P_{n d}
$$

where $P_{n a}, P_{n b 1}, P_{n b 2}, P_{n b 3}, P_{n c}, P_{n d}$, are the contract execution ability indicators of the node enterprises $a, b 1, b 2, b 3, c, d$, respectively, when facing $n$ competitors.

As an enterprise's profitability changes with the operating environment and each enterprise's situation, the ability to execute SCN contracts has dynamic attributes.

\subsubsection{SCN Information Interactive Ability}

Research has shown that information interactivity is very important for successful supply chain integration [48-51]. With the increasing integration of digital networks and physical entities, a new type of network, shown as Figure 6, was proposed, which connects information, resources, entities and human beings, supports the automatic delivery of information to the SCN production elements and promotes SCN integration and optimization throughout the complete lifecycle. This structure integrates the information into networks using cloud computing and emphasizes collaboration between the information network system and the physical system. 


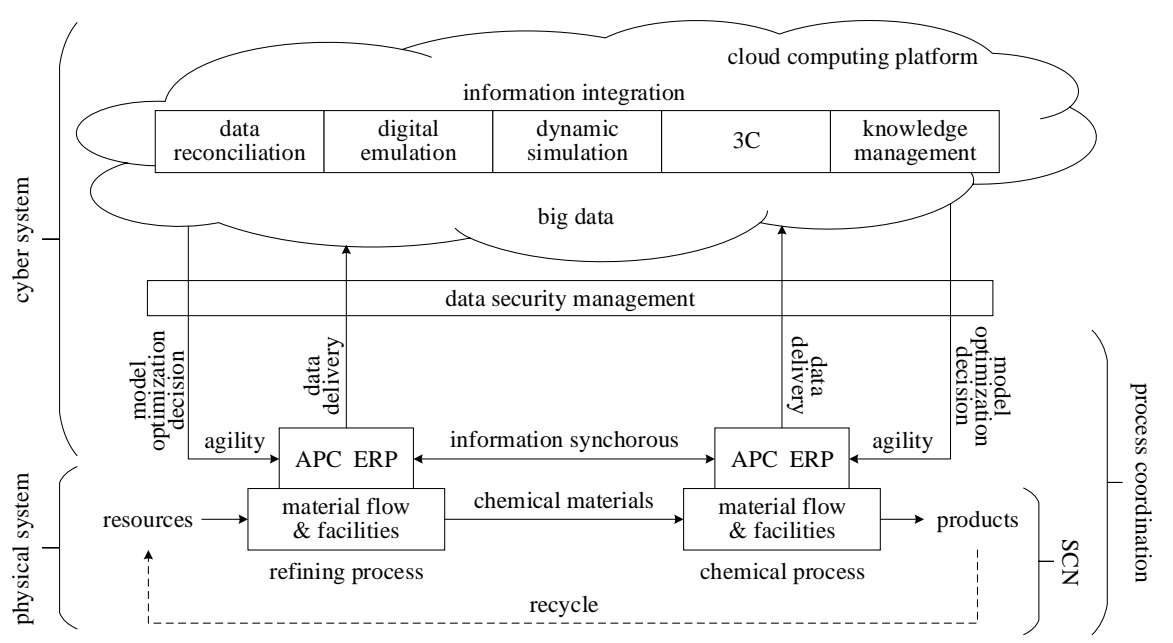

Figure 6. The information interaction architecture facing SCN.

In summary, SCN collaborative evaluation is useful for sophisticated planning and operations management as by evaluating the SCN collaboration level, enterprises seeking to enter an industrial park can be carefully selected in the planning phase. Additionally, dynamic collaborative evaluations conducted during operations can detect and eliminate risks.

\section{Coal Industry SCN Evaluation Models}

Taking the coal industry as shown in Figure 2 as an example, the SCN model was established as in Figure 7, in which the petrochemical industry is the system competitor. The coal industry SCN was analyzed based on the methods outlined in Section 2.

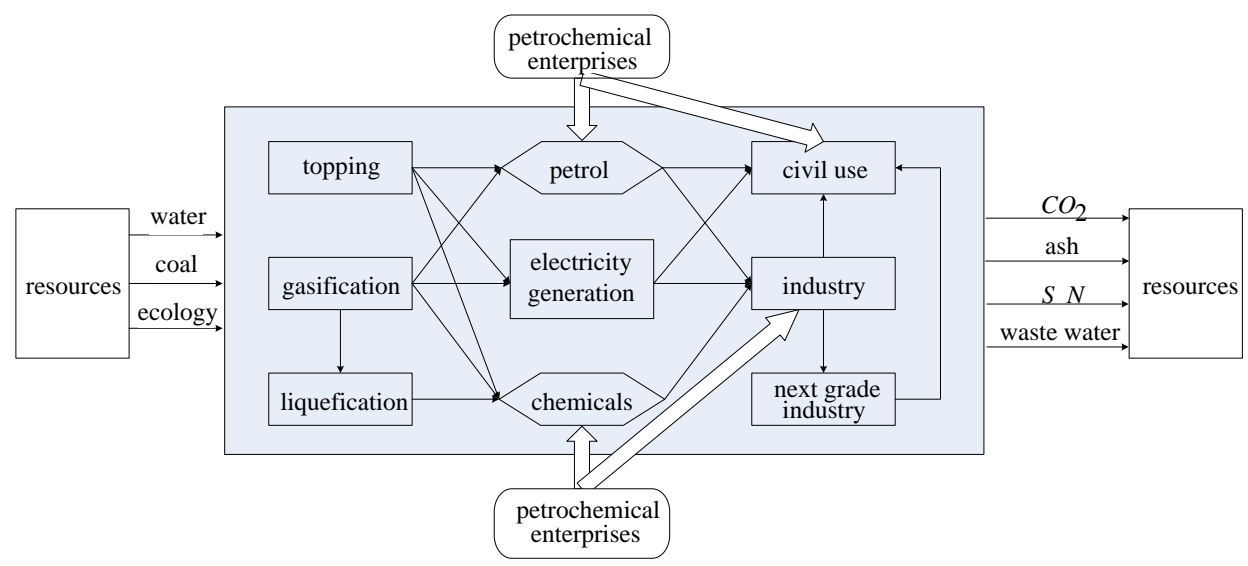

Figure 7. Coal chemical industry SCN structure.

\subsection{Industry Metabolic Balance Analysis}

On the basis of the coal industry product structure, technical routes and equipment operating conditions, dioxide emissions are selected to evaluate the industry metabolic balance. $\mathrm{As} \mathrm{CO}_{2}$ comes mainly from the utilization of fossil energy [52], $\mathrm{CO}_{2}$ emissions are considered to be a strong correlation index for coal industry industrial metabolic balance. For data accuracy and the necessity to reflect the carbon balance across the whole industry, China, Japan and America were taken as examples to calculate the results using Equation (1) (Table 1). 
Table 1. Industrial metabolic balance for carbon dioxide.

\begin{tabular}{lcccccc}
\hline & $\begin{array}{c}\text { Petrochemical Resource } \\
\text { Consumption (Mtonne of } \\
\text { Standard Coal Equivalent) }\end{array}$ & \multicolumn{2}{c}{$\begin{array}{c}\mathbf{C O}_{\mathbf{2}} \text { Emissions } \\
\text { (Mtonne) }\end{array}$} & \multicolumn{2}{c}{$\begin{array}{c}\text { Carbon } \\
\text { Balance-Degree of } \\
\text { Industrial Metabolism }\end{array}$} \\
\cline { 2 - 7 } & $\mathbf{2 0 1 1}$ & $\mathbf{2 0 1 2}$ & $\mathbf{2 0 1 1}$ & $\mathbf{2 0 1 2}$ & $\mathbf{2 0 1 1}$ & $\mathbf{2 0 1 2}$ \\
\hline CHN & 3171 & 3460 & 8324 & 8640 & 0.286 & 0.318 \\
USA & 2662 & 2620 & 5433 & 5341 & 0.443 & 0.444 \\
JAP & 576 & 591 & 1171 & 1180 & 0.445 & 0.455 \\
\hline
\end{tabular}

(Data resources: World Bank Database).

In Table 1, the carbon industry metabolism in China is lower than in either America or Japan because China's low-carbon technologies need further improvements and China's energy sector is characterized by abundant coal and less oil, resulting in greater $\mathrm{CO}_{2}$ emissions.

The carbon industry metabolic balance can be improved by strengthening the carbon utility inside the SCN. Xie developed a new method for carbon capture and utilities (CCU) to reduce $\mathrm{CO}_{2}$ emissions which focused on the $S$-based compound fertilizer being produced by mineralizing solid wastes phosphogypsum and $\mathrm{CO}_{2}$ [53]. The chemical reaction was as in Equations (12) and (13) with the magnesium chloride conversion rate being up to $100 \%$ under $600{ }^{\circ} \mathrm{C}$.

$$
\begin{gathered}
\mathrm{MgCl}_{2} \cdot 6 \mathrm{H}_{2} \mathrm{O} \rightarrow \mathrm{Mg}(\mathrm{OH})_{2}+4 \mathrm{H}_{2} \mathrm{O}+2 \mathrm{HCL} \\
\mathrm{Mg}(\mathrm{OH})_{2}+\mathrm{CO}_{2} \rightarrow \mathrm{MgCO}_{3}+\mathrm{H}_{2} \mathrm{O}
\end{gathered}
$$

Xie et al. found that about 0.125 billion tonnes of $\mathrm{CO}_{2}$ could be mineralized in China using 0.5 billion tons of phosphogypsum, thereby improving the carbon metabolic balance by about $13.5 \%$. Therefore, if the SCN covers the element's complete life cycle, the overall industry metabolic balance could be improved.

\subsection{Enterprise Profitability Evaluation Based on Grey Relationship Analysis}

Equations (3) and (4) constitute the framework for the SCN sustainable profitability models. When applied, concrete evaluation models are needed. Enterprise profitability models primarily focus on quantitative economic factors. The range of related evaluation indexes that reflect the various enterprise profitability aspects and have a different impact on overall profitability evaluations are listed in Table 2; therefore, a nonlinear time-varying coefficient factor model could be a viable alternative solution [54]. However, as the indices in Table 2 are not independent, the models based on these factors remain extremely complex; therefore, it is necessary to isolate the essential model inputs to establish a concise enterprise profitability evaluation model. Chang developed a hybrid model by integrating Self Organization Map (SOM) neural networks, Genetic Algorithms (GA) and a Fuzzy Rule Base (FRB) to forecast a company's future sales [55]. Marquez created a list of attributes that together defined customer value, and then grouped customers who prioritized the same attributes, thereby improving decision-making and increasing sales, revenue and market share [56]. As a result of the multicriteria evaluations and complicated influencing factors facing the coal industry, the research in this paper used Grey relational analysis (GRA) to remove the lowly correlated, non-independent influencing factors. 
Table 2. Partial evaluation indexes for enterprise's profitability.

\begin{tabular}{|c|c|c|c|}
\hline Item & Evaluation Indexes & Item & Evaluation Indexes \\
\hline E01 & network density & E14 & current ratio \\
\hline E02 & network centralization & E15 & ratio of liabilities to assets \\
\hline E03 & viscosity of brand with customers & E16 & total assets turnover \\
\hline E04 & product quality qualification rate & E17 & current asset turnover \\
\hline E05 & product species diversity & E18 & accounts receivable turnover \\
\hline E06 & products prices & E19 & rate of capital turnover \\
\hline E07 & $\begin{array}{l}\text { prices for the competitive products } \\
\text { (crude oil) }\end{array}$ & E20 & inventory turnover \\
\hline E08 & sales-output ratio & E21 & return on sales \\
\hline E09 & production-demand balance & E22 & ratio of Profits to Cost \\
\hline E10 & products output & E23 & raw material supply timeliness \\
\hline E11 & revenue growth rate & E24 & purchasing lead time \\
\hline E12 & market share & $E 25$ & delivery timeliness \\
\hline E13 & profit rate to net worth & & $\ldots \ldots$ \\
\hline
\end{tabular}

\subsubsection{Grey Relational Analysis of the SCN Influencing Factors}

As stated, as the enterprise evaluation indexes are complex and lack independence, diversified evaluation indicators was required. GRA is a feasible method to eliminate more weakly correlated factors [57] as it measures the relational degrees (IDs) between the different factors based on serial data similarity degrees. Factors which have a lower correlation degree than a certain discriminatory coefficient or a preset correlation degree could be regarded as being weakly correlated factors [58].

According to the GRA, the reference sequence that reflects SCN behavior and the comparative sequence affecting SCN behavior are first determined. The former is expressed as $X_{0}(k), k=1,2, \ldots n$, the latter is expressed as $X_{i}=\left\{X_{i}(k) \mid k=1,2, \ldots n\right\}, i=1,2 \ldots m$. The data for each influential factor are processed using the mean value method and nondimensionalization and normalization. The correlation coefficient is defined as in Equation (14), which identifies the relationships between the influential factors and enterprise profitability.

$$
\xi_{i}(k)=\frac{\operatorname{minmin}_{i}\left|X_{0}(k)-X_{i}(k)\right|+\rho \operatorname{maxmax}_{i}\left|X_{0}(k)-X_{i}(k)\right|}{\left|X_{0}(k)-X_{i}(k)\right|+\rho \max _{i} \max _{k}\left|X_{0}(k)-X_{i}(k)\right|}
$$

where $\xi_{i}(k)$ is the correlation coefficient, for which, the greater the value, the higher the correlation degree, and $p$. is the discrimination coefficient, which is usually set at 0.5 .

Taking China Coal Energy (the Shanghai Stock Exchange, stock code 601898) as an example, the gross profit rate (GPR) was selected as the index for the reference sequence, and the 25 evaluation indexes in Table 2 are the indicators for the comparative sequence, the values for which were calculated based on financial statements. The GPR was calculated using Equation (15)

$$
G P R=100 *(T R-O C) / T R \%
$$

where $T R$ is the total revenue and $O C$ is the operating cost. According to Equation (12), $\xi_{i}(k)$ for the 25 comparative indices were calculated, and the results are presented in Figure 8. It was found that the values for $\xi_{i}(E 06), \xi_{i}(E 07), \xi_{i}(E 10)$ were all larger than 0.8 , indicating that they had a greater impact on the GPR than any other index. Research has shown that there is a competitive relationship between the coal industry and the petrochemical industry, with crude oil prices having a significant impact on coal industry profitability [59], which is in accordance with the calculated values for $\xi_{i}(k)$. 


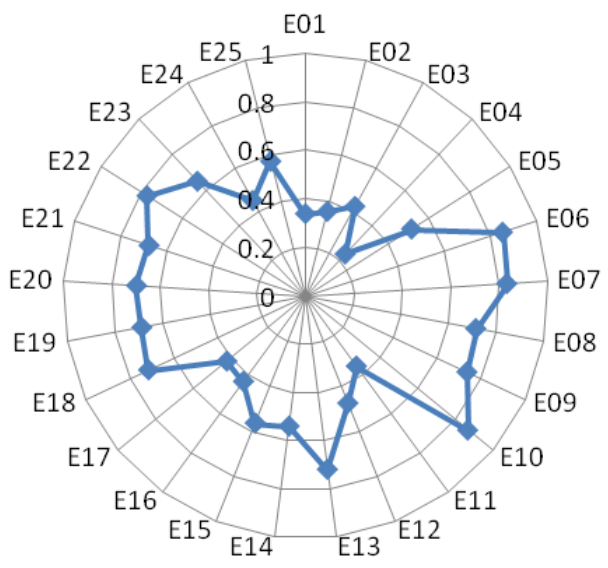

Figure 8. Radar chart for the correlation coefficients for the 25 comparative indexes.

Therefore, from the calculated values for $\xi_{i}(k), E 06, E 07$ and E10 were selected as the key factors for the establishment of the SCN profitability evaluation models. As it is difficult to establish a theoretical model between crude oil prices and coal industry profitability due to unstable and uncertain correlations, conventional regression models were unable to achieve an ideal correlation model.

To compensate for the drawbacks in traditional linear and nonlinear regression models, there has been increased attention on the use of artificial intelligence (AI) techniques such as artificial neural networks, fuzzy logic, genetic algorithms and hybrid models. In this study, hybrid genetic algorithms (GA) and a back-propagation artificial neural network were applied.

\subsubsection{Profitability Model Based on the GA-BP}

The back-propagation artificial neural network (BP-ANN) is a large-scale nonlinear dynamic system consisting of a number of interconnected simple nonlinear processing elements that have adjustable strength, the independent and dependent variables for which are respectively the input values and output values of the network. BP-ANN is good at dealing with unstructured and uncertain relationships; for example, an improved neural network algorithm has been used to establish performance evaluation models for a green supply chain in an uncertain environment [59].

Different from regression algorithms that use statistical regression to establish the mathematical relationship models between the causal variables, BP-ANN has various input nodes and one or several output nodes, which represent the mapping relationships between the independent and dependent variables. BP-ANN uses a gradient descent method and an error backpropagation algorithm to adjust the weights and thresholds on each layer to ensure the outputs are closer to expected values and to accelerate convergence. BP-ANN is therefore applied to build the enterprise profitability models, with the output nodes being the SCN evaluation indexes, and the input nodes being the influencing factors from the SCN evaluation models listed in Table 2. To eliminate interference and improve accuracy, the key factors identified by the GRA are selected as the input nodes, with the GPR as the output node.

As a random search method based on the biological evolution [60], genetic algorithms (GAs) have a remarkable ability to escape the local optima and find a global optimal solution that minimizes the differences between the actual and calculated values; therefore GAs have become increasingly popular for solving optimization problems [61,62]. As they use the survival of the fittest principle, GAs guide the search to the most promising areas in the stated space, accelerating the dynamic optimization process for the BP-ANN weights and thresholds [63]; therefore, in this study a GA and BP-ANN were combined to improve the models' accuracy and convergence, the hybrid algorithm for which is shown in Figure 9. 


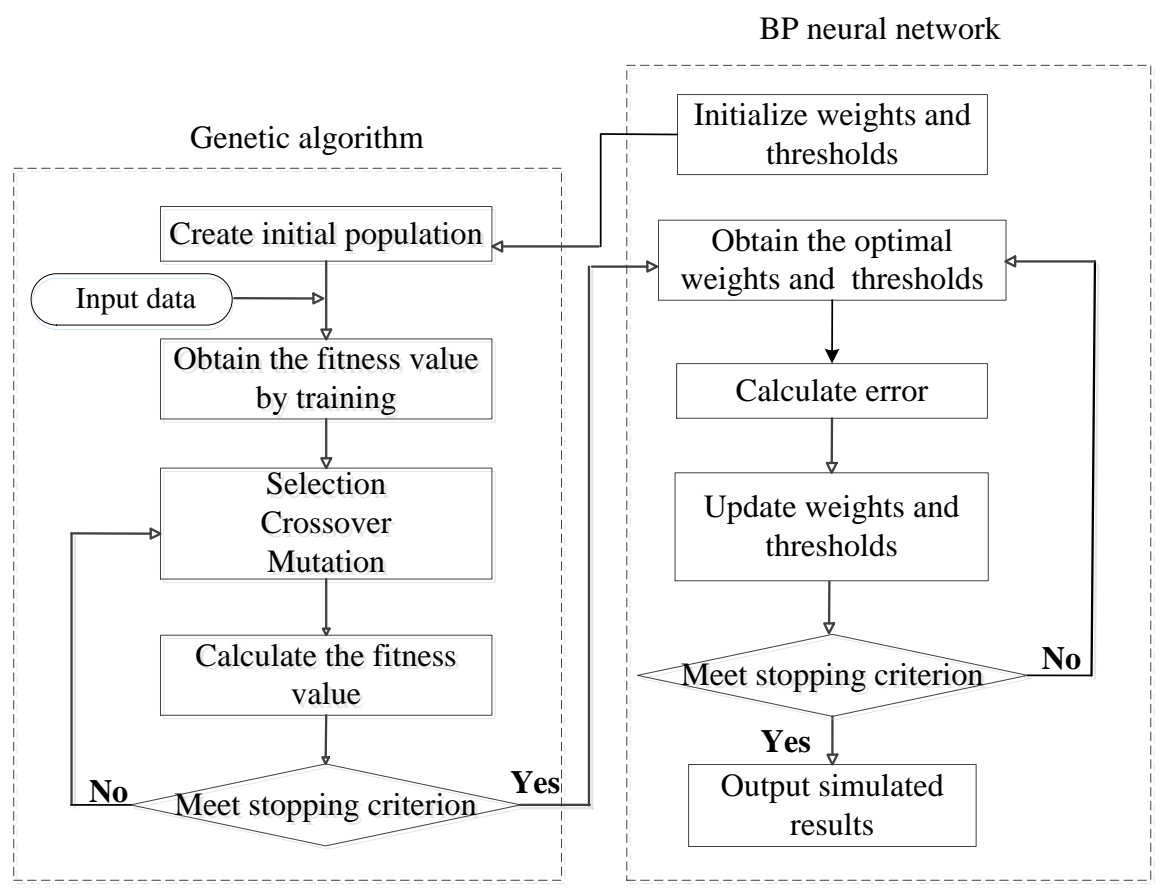

Figure 9. Hybrid algorithm of genetic algorithm (GA) and back-propagation artificial neural network (BP-ANN).

To evaluate the accuracy of the model, the root-mean-square error (RMSE) and the R-square coefficient $\left(R^{2}\right)$ of the output were calculated (Yuan et al., 2014).

RMSE is used to measure the deviation between the simulated values and the true values, and is given by Equation (16).

$$
R M S E=\sqrt{\frac{1}{N} \sum_{i=1}^{N}\left(O_{i}-t_{i}\right)^{2}}
$$

$R^{2}$ is a measure of how well the independent variables account for the measured dependent variable and is determined using Equation (17).

$$
R^{2}=1-\frac{\sum_{i=1}^{N}\left(O_{i}-t_{i}\right)^{2}}{\sum_{i=1}^{N}\left(O_{i}\right)^{2}}
$$

where $t_{i}$ is the true value of GPR, $O_{i}$ is the simulated value and $N$ is the total number of data points.

In this article, China Coal Energy (CCE, stock code: 601898), China Shenhua Energy Company Limited (CSEC, stock code: 601088) and Yanzhou Coal Mining Company Limited (YanzCoal, stock code: 600188) were selected as the research objects, with a time period ranging from the first quarter 2012 (2012Q1) to first quarter 2015 (2015Q1). Data from 2012Q1 to 2014Q2 were chosen as the BP-ANN training data, and data from 2014Q3 to 2015Q1 were selected as the test values. The BP-ANN simulated results are listed in Table 3. The RMSE was 0.0231 and the $R^{2}$ was 0.998 , indicating that there were deterministic relationships between the GPR and E06,E07,E10. As the influential factors for the coal industry GPR are complex, the above relationships are only reflections of certain situations under established technical and equipment conditions; however, whether these results have a wider adaptability range needs to be verified with additional samples. The average relative error was $-2.32 \%$. Figure 10 shows the relative errors in the GPR output values for the BP-ANN models in comparison to the real values, indicating that the BP-ANN-based enterprise profitability model is feasible, and proving that there are significant correlations between the coal chemical industry earning ability and crude oil prices, coal prices and coal output. 
Table 3. Test values for the BP-ANN based gross profit rate (GPR) for coal chemical companies.

\begin{tabular}{|c|c|c|c|c|c|c|c|c|c|}
\hline \multirow[b]{2}{*}{ Quarter } & \multirow{2}{*}{$\begin{array}{c}\text { E10 } \\
\text { Coal Output } \\
\text { (Gigatonne) }\end{array}$} & \multirow{2}{*}{$\begin{array}{c}\text { E06 } \\
\text { Coal Price } \\
\text { (RMB/Tonne) }\end{array}$} & \multirow{2}{*}{$\begin{array}{c}E 07 \\
\text { Oil Price } \\
\text { (Dollar/bbl) }\end{array}$} & \multicolumn{2}{|c|}{ CCE } & \multicolumn{2}{|c|}{ CSEC } & \multicolumn{2}{|c|}{ YanzCoal } \\
\hline & & & & GPR & $\begin{array}{c}\text { ANN } \\
\text { Output }\end{array}$ & GPR & $\begin{array}{c}\text { ANN } \\
\text { Output }\end{array}$ & GPR & $\begin{array}{c}\text { ANN } \\
\text { Output }\end{array}$ \\
\hline 2012Q2 & 1.072 & 491 & 108.42 & $34.3 \%$ & - & $37.4 \%$ & - & $27.2 \%$ & - \\
\hline 2012Q3 & 0.97 & 442 & 109.61 & $35.5 \%$ & - & $37.8 \%$ & - & $23.3 \%$ & - \\
\hline 2012Q4 & 0.77 & 438 & 110.09 & $36.2 \%$ & - & $36.0 \%$ & - & $24.1 \%$ & - \\
\hline 2013Q3 & 0.98 & 400 & 110.27 & $32.8 \%$ & - & $35.0 \%$ & - & $21.7 \%$ & - \\
\hline 2013Q4 & 0.91 & 416 & 109.21 & $31.8 \%$ & - & $33.9 \%$ & - & $22.3 \%$ & - \\
\hline 2014Q1 & 0.85 & 401 & 108.17 & $35.1 \%$ & - & $34.8 \%$ & - & $17.1 \%$ & - \\
\hline 2014Q2 & 0.966 & 363 & 109.70 & $32.6 \%$ & - & $35.0 \%$ & - & $17.2 \%$ & - \\
\hline 2014Q3 & 1.034 & 340 & 101.82 & $30.7 \%$ & $29.9 \%$ & $34.0 \%$ & $34.9 \%$ & $18.7 \%$ & $18.6 \%$ \\
\hline 2014Q4 & 0.102 & 364 & 76.40 & $30.0 \%$ & $28.8 \%$ & $34.3 \%$ & $35.4 \%$ & $19.1 \%$ & $21.2 \%$ \\
\hline
\end{tabular}

(Data resources: the financial statements of the listed company. The price is the average for the quarter).

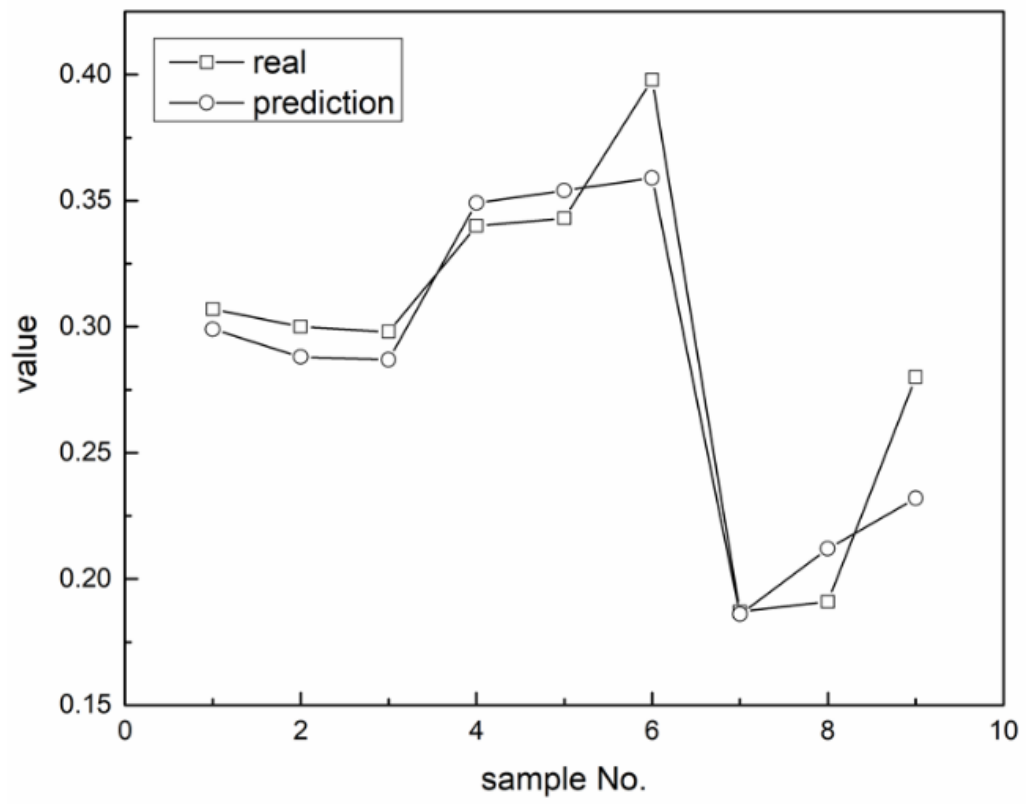

Figure 10. Relative error for the GPR output values vs. the real values.

Figure 11 shows that the GPR value trends for the companies since 2006 were decreasing year on year, which was primarily due to overcapacity in China's coal chemical industry. The GPR for CCE and CESC are better than for YanzCoal, indicating a more stable profit-earning ability. The two petrochemical companies, coming from more competitive industries, (Sinopec and Yueyang Xingchang Petro-chemical Co. Ltd., Yueyang, China) have a more stable GPR because of better SCN integration. It could be concluded, therefore, that to achieve sustainable profitability, the coal chemical industry should have strong capital integration with the petrochemical industry to improve industrial SCN integration and financial profit-earning and to increase the ability to combat risks. 


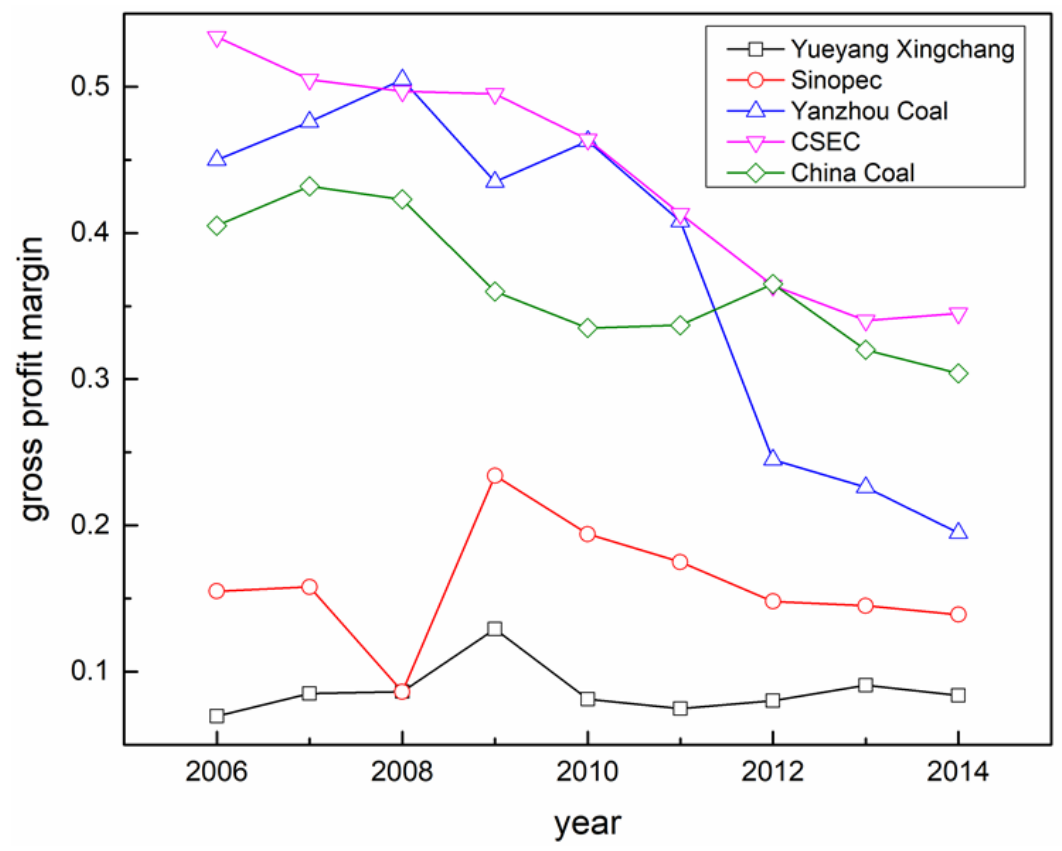

Figure 11. GPR for the coal chemical companies.

In summary, crude oil and coal prices are significant influential factors for enterprise profitability in the coal chemical industry; with this in mind, the profitability evaluation models could be simplified to Equation (18).

$$
P_{i}=f\left(P_{\text {coal }}, P_{\text {oil }}, Q_{\text {coal }}\right)
$$

where $P_{i}$ is the contract execution ability indicator of node enterprise $i$ in facing the competitors, $P_{\text {coal }}$ is the coal price, $P_{\text {oil }}$ is the crude oil price and $Q_{\text {coal }}$ is the coal output.

\subsection{Contract Execution Ability Evaluation}

To analyze SCN contract execution ability, the contracts need to truncate the network chain into its basic relationship structure through the selection of the core enterprise nodes to develop an independent sub-network. The SCN chains shown in Figure 7 are truncated, with gasoline, diesel oil and olefin being the core nodes, as shown in Figure 12:

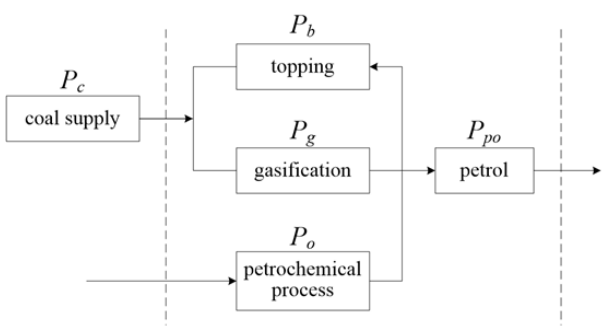

(a) Petrol subnetworks of coal SCN

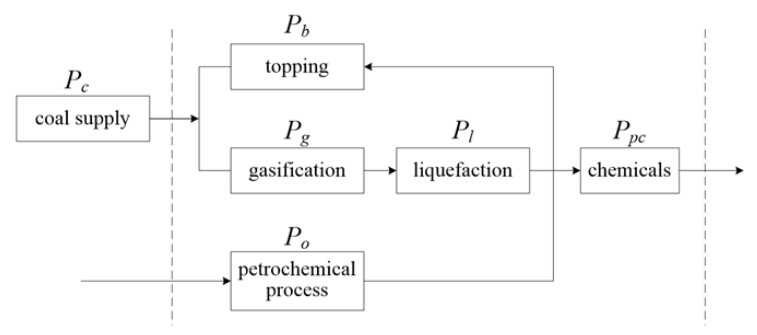

(b) Chemicals subnetworks of coal SCN

Figure 12. Truncated SCN chains.

The execution contract abilities of mode (a) Pertrol subnetworks of coal SCN and (b) Chemicals subnetworks of coal SCN can be calculated using Equations (19) and (20):

$$
\begin{gathered}
P_{t a}=P_{c} \times\left(\min \left\{P_{b}, P_{g}, Q_{o}\right\}\right) \times P_{p o} \\
P_{t b}=P_{c} \times\left(\min \left\{P_{b}, P_{g} \times P_{l}, Q_{o}\right\}\right) \times P_{p c}
\end{gathered}
$$


The comprehensive SCN contract execution ability is

$$
P=\max \left\{P_{t k} \mid k=1,2, \ldots, n\right\}
$$

where $P_{c}$ is the contract execution ability index for the coal supply node, $P_{b}$ is the contract execution ability index for the light fraction separation node, $P_{g}$ is the contract execution ability index for the gasification node, $P_{l}$ is the contract execution ability index for the liquefaction node, $P_{o}$ is the contract execution ability index for the petrochemical process node, $P_{p c}$ is the contract execution ability index for the chemicals node, $P_{t a}$ and $P_{t b}$ are the contract executions in subnetworks (a) and (b) as shown in Figure 12, respectively, $P_{t k}$ is the contract execution in subnetwork $k, k$ is $1,2 \ldots, n$, with $n$ being the maximum number of independent $\mathrm{SCN}$ subnetworks, and $P$ is the complete overall SCN contract execution.

\subsection{Information Interactive Ability Evaluation}

The information interactive ability can be evaluated using investment intensity and the information project business scopes. In this paper, the $\mathrm{SCN}$ information interactive ability was calculated using Equation (22):

$$
I_{n}=\frac{\sum_{i=1}^{n} \frac{I_{i}}{R_{i}}}{n}
$$

where $I_{i}$ is the information project investment intensity for enterprise $i, R_{i}$ is the revenue from enterprise $i$ and $n$ is the number of the SCN enterprises. From Equation (20), the investment intensity of CCE is $0.25 \%$, and that of YanzCoal and CSEC are $0.16 \%$ and $0.19 \%$, respectively. From these results, it could be surmised that lower investment intensity is one of the reasons that YanzCoal has a lower GPR. The qualitative evaluation indexes listed in Table 4 are proposed to evaluate the information interactive ability which can be analyzed using the Delphi method.

Table 4. Qualitative evaluation indexes for information interactive ability.

\begin{tabular}{cc}
\hline Evaluation Method & Evaluation Indexes \\
\hline & Information Openness \\
Qualitative evaluation & Accuracy and agility of information \\
& Value of information sharing \\
Information integration \\
Information content and intensity
\end{tabular}

Combined with the model and method proposed in this paper, the following experiences can be applied: (1) Comprehensively use oil, natural gas, clean energy, etc., and constantly optimize the energy structure; (2) formulate scientific and reasonable countermeasures, adopt advanced technology, continuously improve the quality of coal, realize energy conservation and emission reduction, and meet the green and sustainable development; (3) accelerate the development of advanced capacity, speed up the development of advanced capacity, provide adequate and stable supply of coal, and further accelerate the construction of the base of coal industry on the basis of the use of advanced technology and equipment, and combine the big data and Internet plus to make the coal industry develop towards the direction of information, intelligence and technology; (4) reorganize coal, steel, building materials and other related industries, give full play to the role of advantageous enterprises, develop and integrate all kinds of favorable resources, coordinate the relationship between upstream and downstream, cooperate with related industries, continuously extend the industrial chain and realize the intensive development of industries. 


\section{Conclusions}

As it is difficult to evaluate the collaboration in coal industry supply chains using single-core supply chain models, a multinode, no-core, correlation, conditional SC mode, known as a supply chain network (SCN), was proposed, for which associated collaborative evaluation models were developed. Compared with previous SCN evaluation models, the models presented in this paper had the following features and advantages.

(1) For thermodynamic equilibrium, material balances, and process conditions, coal chemical processes must have rigid constraints and strong collaboration between the supply chain node enterprises; therefore, the multinode, no-core, correlation condition supply chain network mode is more suitable compared to previous modes which primarily focus on material flows. Cooperative, competitive and cooperative-competitive SCN modes were discussed and examined. Through the above mode analysis, the more reasonable supply chain could be constituted, and the operational risks could be precontrolled.

(2) As a result of coal chemical industry characteristics such as correlation, conditionality and atomic economy, this paper examined the supply chain networks from the atomic level to system level, and established related evaluation models which took account of industrial metabolic balances, enterprise sustainable profitability, contract execution ability and information interaction abilities. In this study, the industrial metabolic balance degree, the enterprise profitability indexes and the contract execution ability indexes were defined, and respective computational formulas developed. The proposed evaluation models in this paper form the scientific and quantitative evaluation method of SC, which could be used for both SC planning and operations management helping detect and eliminate risks.

(3) Based on the technological economic characteristics of the coal chemical industry, the industrial metabolic balance was used as the efficiency index for SCN resource coordination, and as the evaluation models' constraints on the system levels, the industrial metabolic balance met the requirements for clean efficient resource utilization. In this study, the SCN industrial metabolic balance was defined by the effective chemical element utilization rate, which was a combination of the product metabolism and waste metabolism rates. The industrial metabolic balance evaluation is the important distinction between the evaluations models of chemical industrial supply chain and that of other types of supply chains, such as the logistics industry.

(4) As the enterprise evaluation indexes were complex and non-independent, on the basis of enterprise actual operation data, GRA was used to analyze the SCN influential factors to remove the weakly correlated factors and the independent factors. BP-ANN was used to deal with the unstructured and indeterminate collaborative relationships. In the case analysis, crude oil prices, coal prices and coal output were found to be the key factors affecting enterprise profitability in the three coal chemical enterprises, and the hybrid algorithm of GA and BP-ANN confirmed the relationships between the output layer and the input layers, with the RMSE calculated at 0.0231 , the $R^{2}$ at 0.998 , and the average prediction error at $-2.32 \%$. The results indicated that the BP-ANN algorithm was feasible for SCN profitability analysis, and could also be used in other SC problems which are not suitable for fitting modeling method.

Author Contributions: Conceptualization, X.J. and L.Z.; methodology, G.H.; software, G.H.; validation, Y.D. (Yiyang Dai); formal analysis, Y.D. (Yagu Dang); investigation, Y.D. (Yagu Dang); data curation, G.H.; writing-original draft preparation, G.H.; writing—review and editing, X.J.; visualization Y.D. (Yiyang Dai); supervision, L.Z.; project administration, X.J.; funding acquisition, X.J. All authors have read and agreed to the published version of the manuscript.

Funding: This research was funded by Key Lab of Process Analysis and Control of Sichuan Universities, grant number 2016003.

Acknowledgments: The authors gratefully acknowledge the support of the National Natural Science Foundation, China (No. 51473102).

Conflicts of Interest: The authors declare no conflict of interest. 


\section{References}

1. Zhou, R.-J.; Li, L.-J. Joint capacity planning and distribution network optimization of coal supply chains under uncertainty. AIChE J. 2018, 64, 1246-1261. [CrossRef]

2. Qu, Y.; Yu, Y.; Appolloni, A.; Li, M.; Liu, Y. Measuring green growth efficiency for Chinese manufacturing industries. Sustainability 2017, 9, 637. [CrossRef]

3. Wu, X.F.; Chen, G.Q. Coal use embodied in globalized world economy: From source to sink through supply chain. Renew. Sustain. Energy Rev. 2018, 81, 978-993. [CrossRef]

4. Appolloni, A.; Sun, H.; Jia, F.; Li, X. Green Procurement in the private sector: A state of the art review between 1996 and 2013. J. Clean. Prod. 2014, 85, 122-133. [CrossRef]

5. Cheng, W.; Appolloni, A.; D'Amato, A.; Zhu, Q. Green public procurement, missing concepts and future trends-A critical review. J. Clean. Prod. 2017, 176, 770-784. [CrossRef]

6. Wang, C.; Zhang, L.; Zhou, P.; Chang, Y.; Zhou, D.; Pang, M.; Yin, H. Assessing the environmental externalities for biomass- and coal-fired electricity generation in China: A supply chain perspective. J. Environ. Manag. 2019, 246, 758-767. [CrossRef] [PubMed]

7. Rioux, B.; Galkin, P.; Murphy, F.; Pierru, A. Economic impacts of debottlenecking congestion in the Chinese coal supply chain. Energy Econ. 2016, 60, 387-399. [CrossRef]

8. Hu, S.; Chen, D.; Jin, Y.; Zhu, B.; Ma, S.; Song, X.; Chen, Z. Green development strategies for chemical industry in China: Based on analysis of fertilizer industry and coal chemical industry. Huagong Xuebao CIESC J. 2014, 65, 2704-2709.

9. Wang, S.K.; Chen, G.H. Risk assessment of industry chain and its application in chemical industrial parks. J. Chem. Eng. Chin. Univ. 2014, 28, 1097-1104. (In Chinese)

10. Kong, Y.; Xie, C.; Zheng, S.; Jiang, P.; Guan, M.; Wang, F. Dynamic early warning method for major hazard installation systems in chemical industrial park. Complexity 2019, 2019, 6250483:1-6250483:18. [CrossRef]

11. Cooper, M.C.; Lambert, D.M.; Pagh, J.D. Supply chain management: More than a new name for logistics. Int. J. Logist. Manag. 1997, 8, 1-14. [CrossRef]

12. Manzini, R.; Gamberi, M.; Gebennini, E.; Regattieri, A. An integrated approach to the design and management of a supply chain system. Int. J. Adv. Manuf. Technol. 2008, 37, 625-640. [CrossRef]

13. Carter, C.; Easton, P. Sustainable supply chain management: Evolution and future directions. Int. J. Phys. Distrib. Logist. Manag. 2011, 41, 46-62. [CrossRef]

14. Silvestre, B. Sustainable supply chain management in emerging economies: Environmental turbulence, institutional voids and sustainability trajectories. Int. J. Prod. Econ. 2015, 167, 156-169. [CrossRef]

15. Ralston, P.; Blackhurst, J.; Cantor, D.; Crum, M. A structure-conduct-performance perspective of how strategic supply chain integration affects firm performance. J. Supply Chain Manag. 2014, 51. [CrossRef]

16. Gong, J.; Yang, Y.; Wang, J. Meeting the challenges to sustain capacity through process integration-Process systems engineering review. Chem. Ind. Eng. Prog. 2006, 25, 721-728.

17. Gardner, T.A.; Benzie, M.; Borner, J.; Dawkins, E.; Fick, S.; Garrett, R.; Godar, J.; Grimard, A.; Lake, S.; Larsen, R.K.; et al. Transparency and sustainability in global commodity supply chains. World Dev. 2019, 121, 163-177. [CrossRef]

18. Lambert, D.; Cooper, M.; Pagh, J. Supply chain management: Implementation issues and research opportunities. Int. J. Logist. Manag. 1998, 9, 1-20. [CrossRef]

19. Gharaei, A.; Karimi, M.; Shekarabi, S.A.H. An integrated multi-product, multi-buyer supply chain under penalty, green, and quality control polices and a vendor managed inventory with consignment stock agreement: The outer approximation with equality relaxation and augmented penalty algorithm. Appl. Math. Model. 2019, 69, 223-254. [CrossRef]

20. Lingron, Z. Influence factors and action mechanism of supply chain technology spillover: A multi-case study based on the self-organizing process of supply chain. J. Manag. Case Stud. 2014, 7, 182-194.

21. Kristianto, Y.; Gunasekaran, A.; Helo, P.; Sandhu, M. A decision support system for integrating manufacturing and product design into the reconfiguration of the supply chain networks. Decis. Support Syst. 2012, 52, 790-801. [CrossRef]

22. Anbanandam, R.; Banwet, D.K.; Shankar, R. Evaluation of supply chain collaboration: A case of apparel retail industry in India. Int. J. Product. Perform. Manag. 2011, 60, 82-98. [CrossRef] 
23. Zokaee, S.; Jabbarzadeh, A.; Fahimnia, B.; Sadjadi, S.J. Robust supply chain network design: An optimization model with real world application. Ann. Oper. Res. 2017, 257, 15-44. [CrossRef]

24. Arampantzi, C.; Minis, I. A new model for designing sustainable supply chain networks and its application to a global manufacturer. J. Clean. Prod. 2017, 156, 276-292. [CrossRef]

25. Tian, Y. Opinions on the development of China's Coal Chemical Industry-Remarks drawn before the 13th five-year plan. Coal Chem. Ind. 2014, 175, 1-8. (In Chinese)

26. Vanany, I.; Zailani, S.; Pujawan, N. Supply chain risk management: Literature review and future research. IJISSCM 2009, 2, 16-33. [CrossRef]

27. Hong, Z.F.; Guo, X.L. Green product supply chain contracts considering environmental responsibilities. Omega Int. J. Manag. Sci. 2019, 83, 155-166. [CrossRef]

28. Laeequddin, M.; Sardana, G.D.; Sahay, B.S.; Abdul Waheed, K.; Sahay, V. Supply chain partners' trust building process through risk evaluation: The perspectives of UAE packaged food industry. Supply Chain Manag. Int. J. 2009, 14, 280-290. [CrossRef]

29. Zhuge, D.; Yu, S.; Zhen, L.; Wang, W. Multi-Period distribution center location and scale decision in supply chain network. Comput. Ind. Eng. 2016, 101, 216-226. [CrossRef]

30. Tang, L.; Jing, K.; He, J.; Stanley, H. Robustness of assembly supply chain networks by considering risk propagation and cascading failure. Phys. A Stat. Mech. Appl. 2016, 459, 129-139. [CrossRef]

31. Ma, Y.; Yan, F.; Kang, K.; Wei, X. A novel integrated production-distribution planning model with conflict and coordination in a supply chain network. Knowl. Based Syst. 2016, 105, 119-133. [CrossRef]

32. Winkler, H. How to improve supply chain flexibility using strategic supply chain networks. Logist. Res. 2009, 1, 15-25. [CrossRef]

33. Farahani, R.Z.; Rezapour, S.; Drezner, T.; Fallah, S. Competitive supply chain network design: An overview of classifications, models, solution techniques and applications. Omega Int. J. Manag. Sci. 2014, 45, 92-118. [CrossRef]

34. Amin, S.H.; Zhang, G.Q. A multi-objective facility location model for closed-loop supply chain network under uncertain demand and return. Appl. Math. Model. 2013, 37, 4165-4176. [CrossRef]

35. Amin, S.H.; Baki, F. A facility location model for global closed-loop supply chain network design. Appl. Math. Model. 2017, 41, 316-330. [CrossRef]

36. Talaei, M.; Moghaddam, B.F.; Pishvaee, M.S.; Bozorgi-Amiri, A.; Gholamnejad, S. A robust fuzzy optimization model for carbon-efficient closed-loop supply chain network design problem: A numerical illustration in electronics industry. J. Clean. Prod. 2016, 113, 662-673. [CrossRef]

37. Li, J.Y.; Wang, L.; Tan, X. Sustainable design and optimization of coal supply chain network under different carbon emission policies. J. Clean. Prod. 2020, 250, 119548. [CrossRef]

38. Ghahremani-Nahr, J.; Kian, R.; Sabet, E. A robust fuzzy mathematical programming model for the closed-loop supply chain network design and a whale optimization solution algorithm. Expert Syst. Appl. 2019, 116, 454-471. [CrossRef]

39. Ahmadzadeh, E.; Vahdani, B. A location-inventory-pricing model in a closed loop supply chain network with correlated demands and shortages under a periodic review system. Comput. Chem. Eng. 2017, 101, 148-166. [CrossRef]

40. Jin, Y.; Wei, F. Sustainable development and ecological process engineering. China J. Nonferous Met. 2004, 14, S1. (In Chinese)

41. Korhonen, J. On the ethics of corporate social responsibility-Considering the paradigm of industrial metabolism. J. Bus. Ethics 2003, 48, 301-315. [CrossRef]

42. Fan, Y.P.; Qiao, Q.; Fang, L. Network analysis of industrial metabolism in industrial park-A case study of Huai'an economic and technological development area. J. Clean. Prod. 2017, 142, 1552-1561. [CrossRef]

43. Zhe, Z. Coal-Based industrial metabolism and ecological optimization. Comput. Appl. Chem. 2001. [CrossRef]

44. Liu, T.; Han, Y.-J. Exploring the relationship among the enterprise operation ability, profitability and development ability. In Proceedings of 2012 3rd International Asia Conference on Industrial Engineering and Management Innovation (IEMI2012); Springer Science \& Business Media: Berlin/Heidelberg, Germany, 2013; pp. 813-821.

45. Cheng, X.J. Simple analysis on some evaluating indexes for enterprise development ability. Pet. Petrochem. Today 2015, 244, 34-39. 
46. Li, Y.-Q.; Fang, P.; Deng, B.-G.; Li, Y. The collaboration evolution mechanism research of industrial chain and innovation chain based on system dynamics. Value Eng. 2015, 21, 79-82. (In Chinese)

47. Mercure, J.-F.; Salas, P. An assessement of global energy resource economic potentials. Energy 2012, 46, 322-336. [CrossRef]

48. Yang, Y.Q.; Jiang, X.Y. Development strategy of China's chemical industries in Merge of Industrialization and Information. Mod. Chem. Ind. 2009, 29, 9-14. (In Chinese)

49. SiWei, C. Improving integration of enterprises by relying on process systems engineering. Mod. Chem. Ind. 1998, 7, 1-5. (In Chinese)

50. Brito Alves, R.; Nascimento, C. Analysis and detection of outliers and systematic errors in industrial plant data. Chem. Eng. Commun. 2007, 194, 382-397. [CrossRef]

51. Ji, X.; He, G.; Xu, J.; Guo, Y. Study on the mode of intelligent chemical industry based on cyber-physical system and its implementation. Adv. Eng. Softw. 2016, 99, 18-26. [CrossRef]

52. Shen, L.; Sun, Y. Review on carbon emissions, energy consumption and low-carbon economy in China from a perspective of global climate change. J. Geogr. Sci. 2016, 26, 855-870. [CrossRef]

53. Xie, H.; Xie, L.; Wang, Y.; Zhu, J.; Liang, B.; Ju, Y. CCU: A more feasible and economic strategy than CCS for reducing $\mathrm{CO}_{2}$ emissions. J. Sichuan Univ. (Eng. Sci. Ed.) 2012, 44, 1-5.

54. Fritsche, U.; Kuzin, V. Analysing convergence in Europe using the non-linear single factor model. Empir. Econ. 2011, 41, 343-369. [CrossRef]

55. Chang, P.-C.; Liu, C.-H.; Wang, Y.-W. A hybrid model by clustering and evolving fuzzy rules for sales decision supports in printed circuit board industry. Decis. Support Syst. 2006, 42, 1254-1269. [CrossRef]

56. Crespo Marquez, A.; Blanchar, C. A decision support system for evaluating operations investments in high-technology business. Decis. Support Syst. 2006, 41, 472-487. [CrossRef]

57. Han, X.; Li, B.; Guan, Z. Atmospheric quality prediction model based on RBF neural network-markov chain of grey correlational analysis filter indexes. Acta Sci. Nat. Univ. Nankaiensis 2013, 46, 22-27.

58. Lin, H.-L. The use of the Taguchi method with grey relational analysis and a neural network to optimize a novel GMA welding process. J. Intell. Manuf. 2012, 23, 1671-1680. [CrossRef]

59. Cao, X. Achieving a healthy development of coal-based chemicals and CTL in China. Chem. Ind. Eng. Prog. 2011, 30, 80-87. (In Chinese)

60. Goldberg, D.E.; Holland, J.H. Genetic algorithms and machine learning. Mach. Learn. 1988, 3, 95-99. [CrossRef]

61. Fu, Z.; Mo, J.-H.; Chen, L.; Chen, W. Using genetic algorithm-back propagation neural network prediction and finite-element model simulation to optimize the process of multiple-step incremental air-bending forming of sheet metal. Mater. Des. 2010, 31, 267-277. [CrossRef]

62. Rao, D.S.H.; Reddy, S.P.V.; Ghorpade, D.V.G.; Reddy, D.C.T. Development of genetic algorithm based hybrid neural network model for predicting the ultimate flexural strength of ferrocement elements. Int. J. Eng. Sci. Technol. 2012, 4, 867-873.

63. Xue, X.; Li, Y.; Yang, X.; Chen, X.; Xiang, J. Prediction of slope stability based on GA-BP hybrid algorithm. Neural Netw. World 2015, 25, 189-202. [CrossRef]

Publisher's Note: MDPI stays neutral with regard to jurisdictional claims in published maps and institutional affiliations.

(C) 2020 by the authors. Licensee MDPI, Basel, Switzerland. This article is an open access article distributed under the terms and conditions of the Creative Commons Attribution (CC BY) license (http://creativecommons.org/licenses/by/4.0/). 